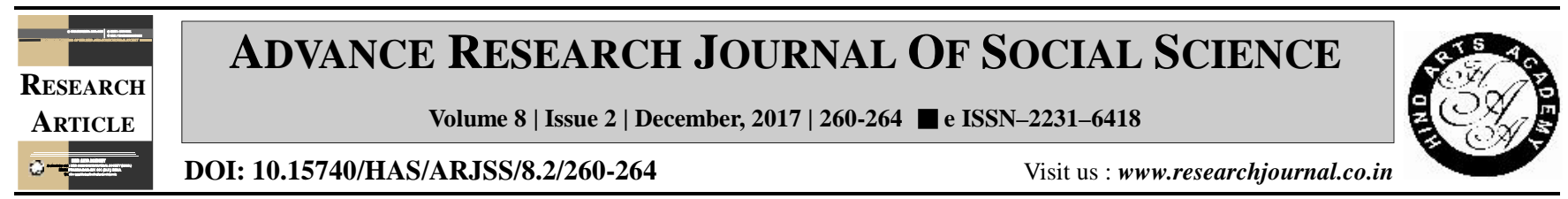

\title{
Experiences of urban teenage girls about menarche
}

Jaya Bangale* and Rohini Waghmare

Department of Human Development and Studies, College of Community Science, Vasantrao Naik Marathwada Krishi Vidyapeeth, PARBHANI (M.S.) INDIA

(Email : bangalejaya@gmail.com)

\section{ARTICLE INFO :}

$\begin{array}{lll}\text { Received } & : & 02.08 .2017 \\ \text { Revised } & : & 15.10 .2017 \\ \text { Accepted } & : & 30.10 .2017\end{array}$

KEY WORDS :

Urban girls, Menarche, Experiences

\section{HOW TO CITE THIS ARTICLE :}

Bangale, Jaya and Waghmare, Rohini (2017). Experiences of urban teenage girls about menarche. Adv. Res. J. Soc. Sci., 8 (2) : 260-264, DOI: 10.15740/ HAS/ARJSS/8.2/260-264.

*Author for correspondence

\begin{abstract}
Two hundred urban teenage girls (15-17yrs) who had attained menarche two years back were selected at random from purposely chosen 1 high school and 4 colleges of Parbhani city, of Maharashtra. The data were collected by personally interviewing the sample girls. The age at menarche of these girls was between 12 yrs. and 13 yrs. Significantly a higher percentage of the middle socio-economic status group (MSES) girls were aware about menarche before its onset and ABOUT menstrual management as compared to their counterpart girls in low socio-economic status group (LSES). Irrespective of the socio-economic status, considerably a lower percentage of the LSES group of urban teenage girls were recorded to have special support particularly with regard to their nutrition, relaxation in doing household chores and affectionate social treatment. The findings of the study advocate that there is a great need to empower girls regarding pubertal changes and how to cope up with them prior to attaining menarche in order to have comfortable and healthy reproductive life. School based sex education programmes are also need to be conducted to provide scientific information about reproductive health care as adolescent girls of today are tomorrow's healthy women, mother, future of the society and great resource of the nation.
\end{abstract}

